\title{
A PROJECT FOR A PROTECTED RE-NOURISHMENT OF THE COASTLINE OF GIARDINI NAXOS, THE TOURISTIC BEACH IN THE NEIGHBOURING AREA OF TAORMINA (NORTH - EASTERN SICILY)
}

\author{
Stefania Lanza, Department of Earth Sciences, University of Messina, lanzas@unime.it \\ Giovanni Randazzo, Department of Earth Sciences, University of Messina, grandazzo@unime.it
}

\begin{abstract}
The municipality of Giardini Naxos, a small town of about 10,000 inhabitants, located in the northern part of the Ionian coast of Sicily, between the cities of Messina and Catania, thanks to its tourism, together with the neighbouring municipality of Taormina, is one of the most important tourist attractions in Italy.In the last few decades the coastline of Giardini Naxos has undergone severe erosion due to problems which have also affected other coastal areas. Furthermore the hard protection structures (emerged breakwaters and groins) which were placed to protect the shoreline have given way to an irregular evolution of the coastline, protecting at times, the area immediately behind, but increasing the erosive phenomena in the neighbouring areas and causing a general and evident decay of the beach. In order to fill the knowledge gap proven by the results of previous interventions, the bay of Giardini Naxos was therefore monitored for almost a year before the beginning of the project. The results showed that the sediments shifted "slightly" from the northern part to the southern part of the bay, partially filling the harbour. The main concern of the town was to find the most ecological way to save the beach: the protection project foresaw an artificial re-nourishment of about 200.000 cubic metres, protected by an $800 \mathrm{~m}$ submerged breakwater placed along the $5 \mathrm{~m}$ isobath and the removal of the existing hard protection structures.
\end{abstract}

Key Words: coastal management, protected beach nourishment, tourist area

\section{Introduction}

Sicily, an island in the middle of the Mediterranean Sea, has always been visited by many tourists because of its beauty, its varied landscape, its cultural and archaeologicalheritage (the highest number of the UNESCO Cultural Heritage sites - 44 - are in Italy and 5 are located in Sicily) and, in recent years for its beautiful beaches. In the last ten years the tourist trend in Sicily has shown a constant presence of about 5 million arrivals which correspond to a presence of about 15 million people who spend at least three nights in official tourist accommodation (Fig. 1). The urban pressure consisting of holiday homes, tourist resorts, marinas and old coastal protection by hard structures (breakwaters, groins and seawalls) have led to down drift erosion, the degradation of beaches and a general loss of economic power. 

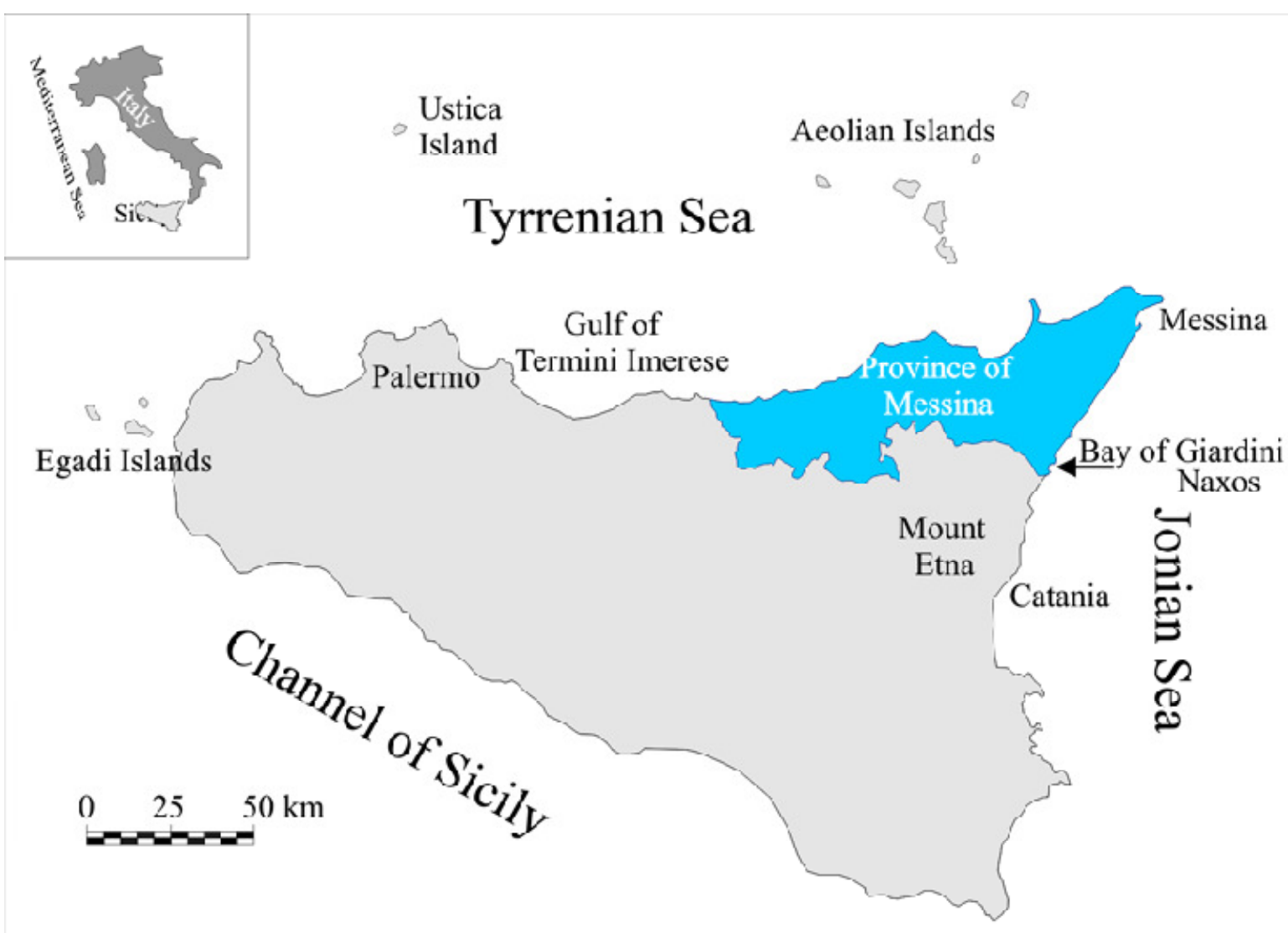

Fig. 1 - Sicily Island.

Between the 1970s and 2000, Sicily underwent erosive processes that concerned several stretches of the coastline and the different solutions proposed to stop them always followed with urgency.

In reality a strategic plan did not exist and defense interventions, through the use of breakwaters, groins and seawalls, were financed, after the call for help by local administrations, by the regional government, sometimes only for political interest.

In the year 2000, a specific EU competition provided the Sicilian littoral with 110 million Euros in investments, in order to remove the causes of erosion and enhance the use of soft protection structures rather than hard ones.

The Sicilian region, after having brought forward an apparently motivated selection, financed 17 intervention projects, but only few solved the problem, while the others obviously failed.

Amongst the financed projects there was also one regarding Giardini Naxos, whose coastline has undergone severe erosion due to the construction of the outer dock of the Schiso port in the southern sector of the bay that changed the local littoral, but also the slight shifting of sediments from the northern to the southern part of the bay, partially infilling the harbour of Schisò itself. Furthermore the hard protection structures which were placed to protect the shoreline have given way to an irregular evolution of the coastline, protecting at times, the area immediately behind, but increasing the erosive phenomena in the neighbouring areas and causing a general 
and evident decay of the beach (Fig. 2). In order to fill the knowledge gap proven by the results of previous interventions, the Bay of Giardini Naxos was therefore monitored for almost a year before the beginning of the project.

The intervention was financed in 2000 , did not manage to remove the causes of the process, i.e. the building of the port first and then the breakwaters, and also the presence of the seaside, allowed the creation of a protection system that suited a tourist area and tried to draw lines of action that could improve coastal management on a regional level.

This paper will describe the area concerned by the intervention, underlining the causes that determined the erosive process and the types of measures put in place. Then the project will be presented with its positive aspects from an environmental point of view and its strong points on a local and regional level.

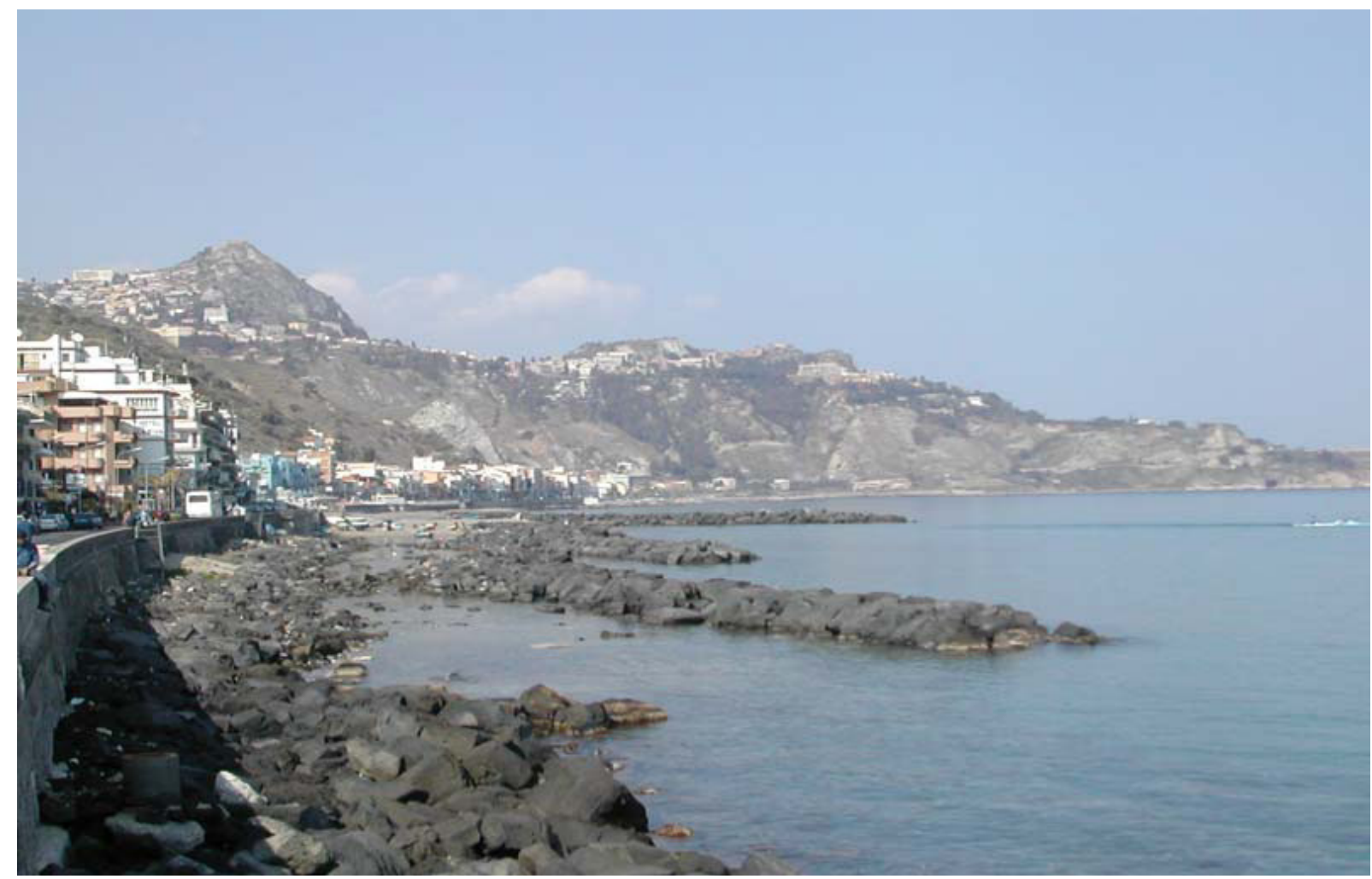

Fig. 2 - Old breakwaters and eroded area.

\section{Geographical setting}

The municipality of Giardini Naxos is a small town (about 10,000 inhabitants), located in the northern part of the Ionian coast of Sicily, between the cities of Messina and Catania. Thanks to its tourism, together with the neighbouring municipality of Taormina, it is one of the most important tourist attractions in Italy. The two municipalities are located on the Bay of Giardini and the tourist flow, which reaches its peak between May and October, registers arrivals of about 442,000 units, who stay in the area on average 4.12 days, in total more than 1.8 million visits a year (A.A.S.T., 2010).

The Bay of Giardini Naxos stretches between Cape Taormina in the North and Cape Schisò in the South. The area hosts many archaeological findings, such as the Greek theatre, the Roman 
thermal baths and the Greek port of Naxos, but also several clubs, luxury shops, more than one hundred hotels, six of which have five stars, and a beach 3 kilometres long, with a NE - SW direction (Fig. 3).

The beach is cut by two limited waterways, Sirina and San Giovanni, and by a semiartificial lengthening locally known as Porticciolo di Saia, and it is boarded by the Tyndaros seaside, that runs along the whole bay.

At the beginning of the last century, the bay had only one continuous beach (falcate),partially protected by several rocks in the central area, that emerged from the depth and rose above the sea level. The bay was also open to the solid materials coming from the Fig. $3-$ The Bay of Giardini Naxos.

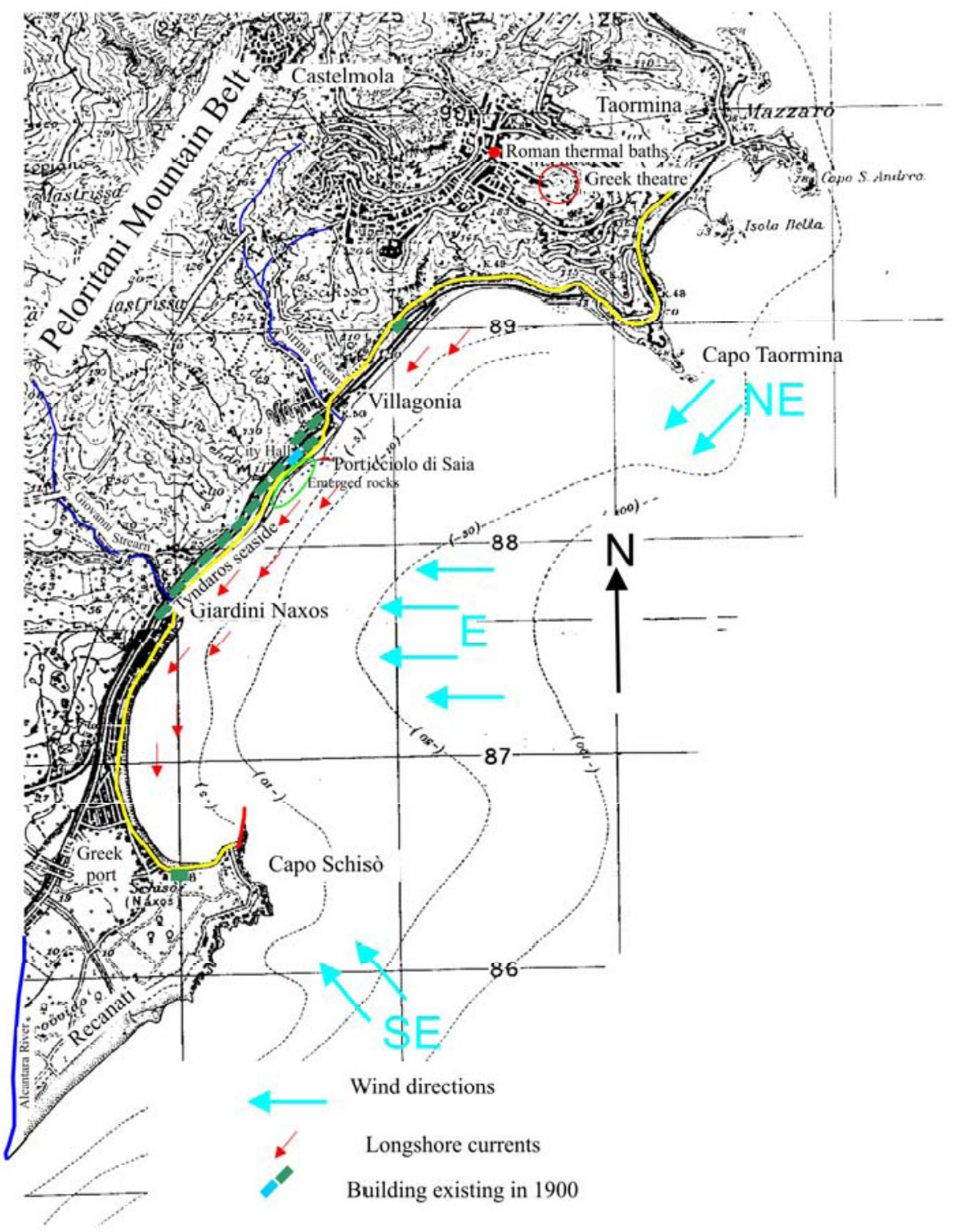

The Alcantara river flows into the sea some hundred metres south of Cape Schisò. 
The natural morphology of the bay is controlled by its geological composition. As a matter of fact, the Bay of Giardini is located in the Peloritani Mountain Belt which is made of metamorphic crystalline rocks which form the Kabilo - Calabride chain. Locally, in the bay, this chain is made of an epimetamorphic Hercynian basement and remnants of mostly carbonate sedimentary covers of Mesozoic - Cenozoic age which constitute the substrate of the town of Taormina and the cliffs that define towards the sea its massif: the Longi - Taormina Unit (AMODIO MORELLI et al., 1976). West and south of the bay the Kabilo - Calabride chain lies directly on the Appenninic - Maghrebian mostly terrigenous substratum (LENTINI et al., 2000, and references therein), made of the Capo d'Orlando Flysch which is composed of conglomeratic quartzarenite banks. Some lava flows of the prehistoric age lie above the latter forming the Cape Schisò promontory.

\section{The causes of erosion}

Between the end of the 1800s and the beginning of the 1900s the Bay of Giardini Naxos had a linear coastline closed in the northern part by Cape Taormina, with sediments brought from the south, and deposited in the sea by the Alcantara river. These sediments overtook the limited lengthening of Cape Schisò and nourished both the beaches near the mouth of the river and the ones within the bay. The studies carried out by D'ARRIGO (1936) confirm these geomorphologic and sedimentological features. The Author compared some bathymetric charts of 1873-1888-1901, underlining the evolution of the beach sediments and the sea beds of the Bay of Taormina (now Giardini Naxos).

During the first decades of the 1900s Giardini Naxos kept its structure of a fishing village, mainly dedicated to the cultivation of citrus fruits and the production of terracotta, and did not undergo the same changes as Taormina, which became one of the most favourite tourist attractions for actors, writers, kings and queens.

In 1958 the port of Schisò started to be built and at the end of the 1970s it was lengthened, even though it has never been ended and it is still not a safe port for the summer months.

But since the port is a lengthening of Cape Schisò, it permanently closes the bay of Giardini Naxos, in the south limiting the winds coming from the south and stopping the sediment flow coming from the Alcantara river. It must also be noted that the urbanisation of the Recanati, south of the port of Schisò, and the reduction of the rate of flow of the Alcantara river, contributed to the reduction of the sediment budget from the south.

During that period, which coincided with the economic boom after the war, the area saw the building of new houses, restaurants, hotels and a seaside, the Bay of Giardini Naxos.

In this context, the main winds, that came from NE and SE, and guaranteed a certain dynamic balance of the beach thanks to the lack of human structures, were no longer pushed from the south and the sediments, mainly transported by the currents coming from the first quadrant, started to move towards the south, leaving in the northern sector exclusively pebbly beaches and moving all the sand into the port of Schisò. In the central sector of the bay (Fig. 4), which is more exposed to sea storms from East, the northern part historically characterized by small beaches was protected by the presence of many rocks above the sea level, while the southern sector of the central area was totally exposed to sea storms and limited by the seaside. All this caused severe erosion, leading to the disappearance of the beach and the collapsing of the seaside, with the dispersion of sediments towards the port of Schisò and off the coast through channels sub-orthogonal to the coast, already identified by D'ARRIGO (1936) 


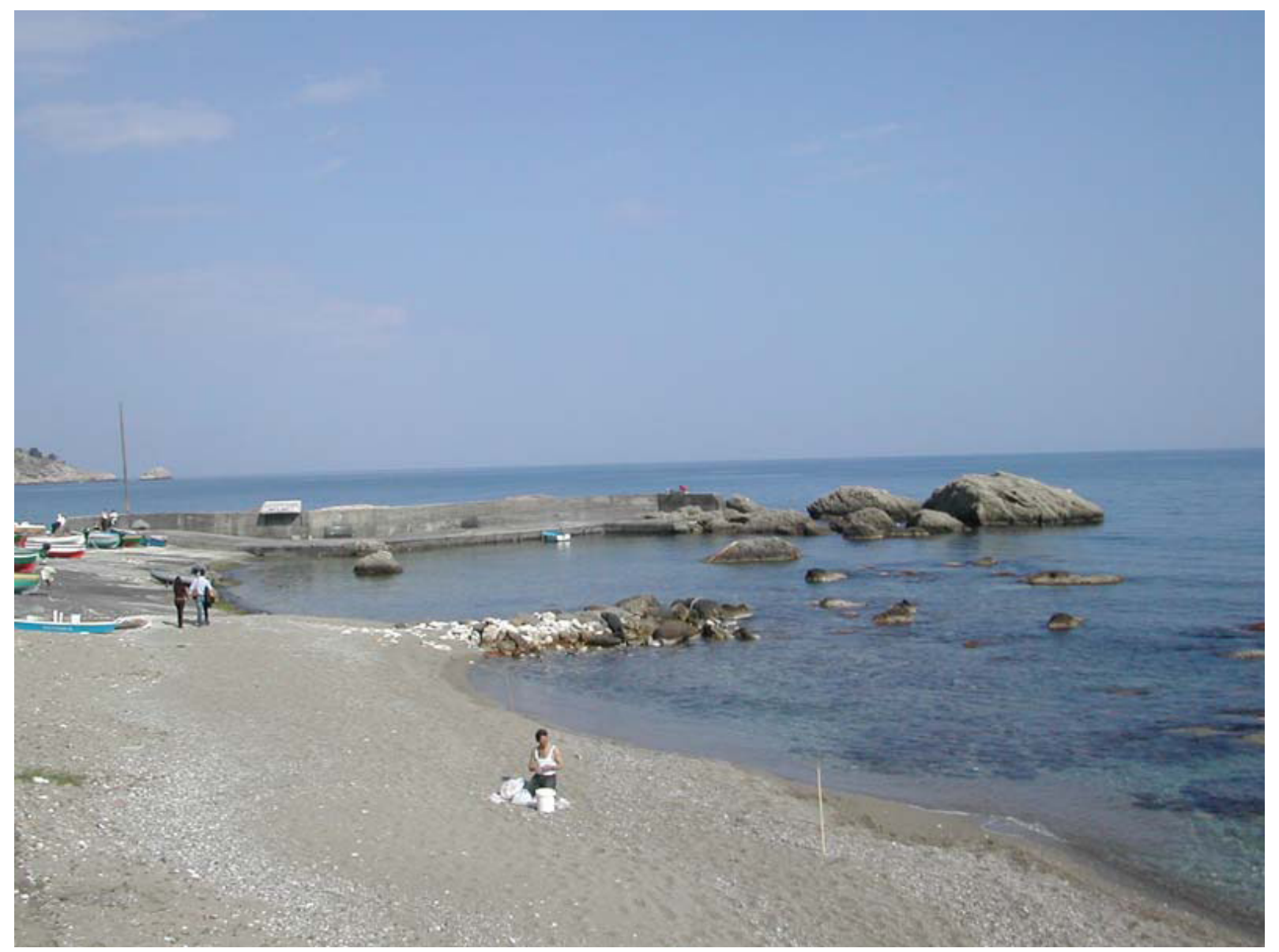

Fig. 4 - Emerged rocks in the central area.

During the last twenty years of the 1900s local administrations, in order to protect the structures already existing, created breakwaters that passively stopped the erosive process, sometimes protecting the seaside (that in any case collapsed two or three times), but without contributing to the creation of a beach that launched tourism in the town that went through long periods of crisis and decay.

\section{The protection system}

At the beginning of the year 2000 the municipality of Giardini Naxos autonomously financed (the only example in Sicily) a study on the erosive process of the bay, in order to single out a protection system to restore the balance of the shoreline and at the same time allow tourists to go to the beach.

The study, carried out by the authors, underlined the evolution described in the previous paragraph and, since it is impossible to remove the port of Schisò and the seaside that supports the shore line, proposes:

- the hauling of the three breakwaters and the submersion of the groins in the area that has to be protected;

- the creation of a submerged parallel barrier to protect the southern sector of the central area; 
- the artificial beach nourishment with materials from the sea bed, both autochthonous (Bay of Giardini Naxos) and allochthonous (submerged deposits outside the Bay).

The hauling will include the complete removal of the breakwaters and the re-use of volcanic rocks to create a submerged barrier. Moreover, the rocks that form the groins above the sea level will be removed (while the submerged barrier was being built, the existing groins were used for it).

The submerged barrier will be 800 meters long, located along the $-5 \mathrm{~m}$ isobath at a distance of around 100-150 metres from the shoreline and it will reduce by $1 / 3$ the wave climate naturally present along the coast (Fig. 5).

Next to this structural intervention, there will be a total beach nourishment of about 250,000 cubic metres of material and an annual recharge after the project between 10 and $20 \%$. Since the area does not have suitable materials both from a granulometric and compositional point of view, it was necessary to identify on a regional level the deposits necessary for the main
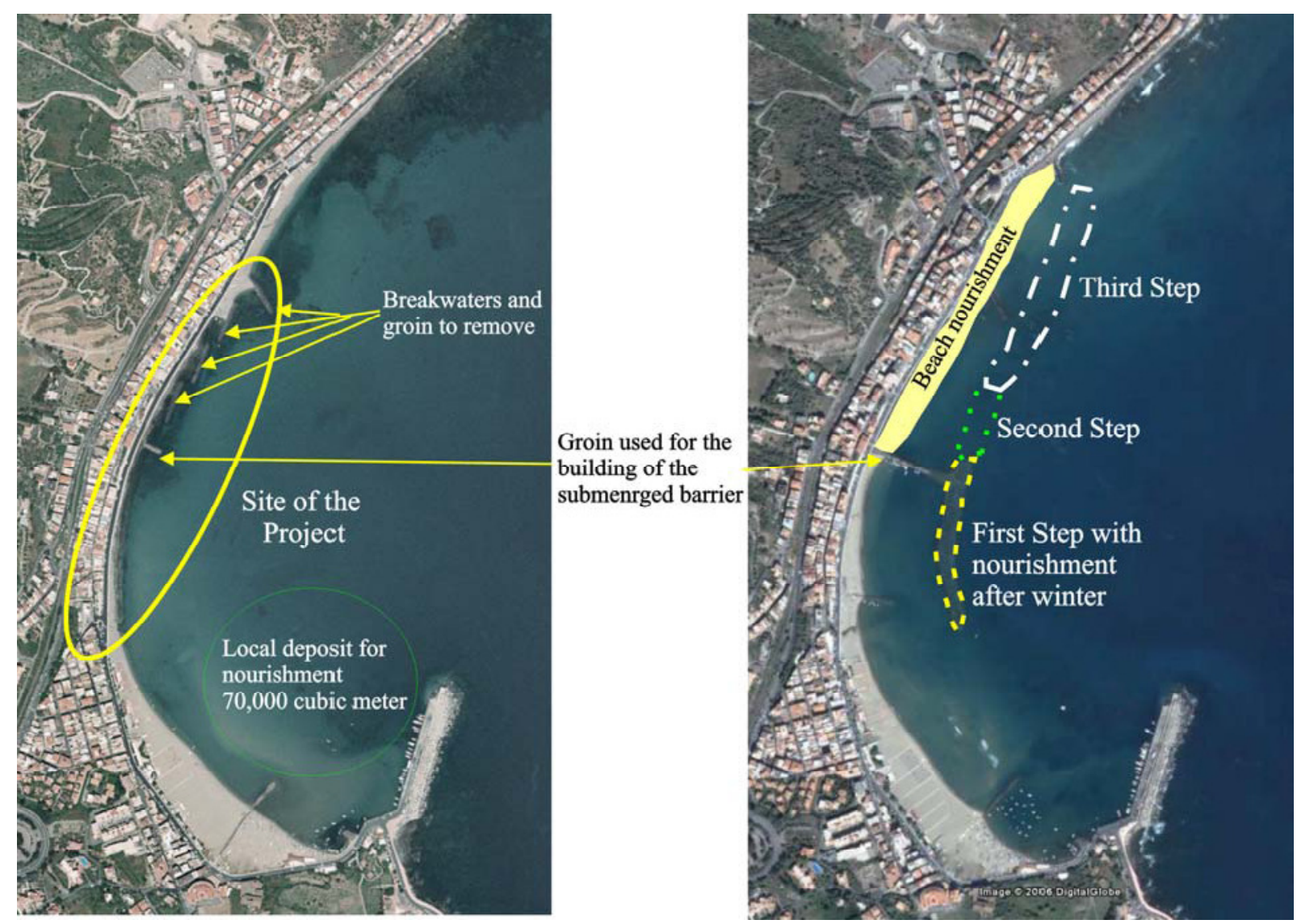

Fig. 5 - Site of the project: in an 1998 Aereal Photo on the left side and from Google Earth (modified) in 2005 on the right side.

intervention. This research was carried out independently by an important company at a national level (Arenaria S.r.I.) which found the materials in the Termini Imerese Gulf. The hinterland of Termini Imerese has a lithology very similar to the one of Giardini Naxos 
(limestone and flysch) and the coast is delimited by a wide continental platform which lacks in the north-eastern part of Sicily, because of the neotectonic activity that concerned it.

The aim of the project was to improve the looks of the littoral, mitigate the wave climate within the protected area and limit the dispersion of sediments outside the bay.

In part the "beach nourishment" choice was made for environmental reasons, but mainly to restore a beach "reserve" of a couple of dozen metres that allow the physiological seasonal transfer between the emerged and submerged beach, preventing erosion. Moreover the "beach nourishment" technique, considering the peculiar geometry of the physiographic unit, is facilitated by the limited longitudinal transport compared to the transversal one.

The choice of a submerged barrier allows a selective dissipation of the swell break that starts $170 \mathrm{~m}$ from the shoreline in correspondence with its external foot and ends at its peak at $150 \mathrm{~m}$ from the shoreline. The barrier also corrects and makes the direction of the swell uniform within the protected area, further limiting the longitudinal displacements of the sediments.

For administrative reasons the project was carried out in three different phases during which a monitoring and maintenance plan was always followed.

In the first phase, that concerned the southern sector of the central area, a section of the submerged barrier was built (around $250 \mathrm{~m}$ ), using natural volcanic blocks and a beach nourishment of about 65,000 cubic metres of materials was put in place in November 2004 (Fig. $6)$.

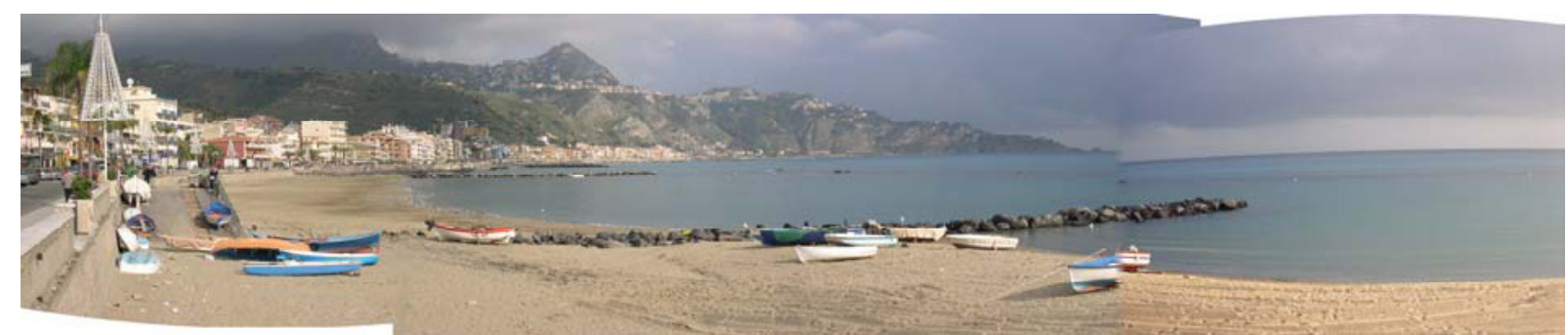

Fig. 6 - Beach at the end of the first phase.

In the second phase the hauling of one of three waterbreaks and the lengthening by $150 \mathrm{~m}$ of the submerged barrier was carried out. This second phase ended in 2008 and for economic reasons the beach nourishment was not brought forward.

The third and last phase of the project foresees the ending of the submerged barrier $(400 \mathrm{~m}$.), the hauling of the other two waterbreaks and the beach nourishment of the protected area. At the end of the third phase the monitoring of the work will be continued in order toidentify the recharge needs and the dispersion of the sediments.

It must be noted that the intervention was monitored seasonally both from a bathimetric and sedimentological point of view, in order to provide a model in -situ useful for the continuation of the project. The continuous monitoring gave effective elements for the analysis of the total stability of the intervention that allowed the introduction of variations that improved the initial project. 
The continuous analysis of the system and the modelling, thanks to the software MIKE21, allowed the project to be refined, enhancing the creation of a system inspired by the integration of the work into the geomorphologic-sedimentological context.

Thanks to this procedure, during the monitoring, great importance was given to the sediments to be used for the artificial beach nourishment and the environmental quality of the intervention.

The resources for the "first step" nourishment were found in the Bay of Giardini Naxos, coming from the sediments that had been eroded over the past few years along the coastline. The materials, amounting to 70,000 cubic metres, were enough for the first phase of the beach nourishment but not to complete the work and its following recharge.

For this reason the sediments along the Termini Imerese Gulf (North of Sicily) were singled out, amounting to 5 million cubic metres and compatible with the ones along the shoreface and the sea-bed of the Bay of Giardini Naxos both from a granulometric (according to JAMES' graphic method, 1975), and from a compositional point of view (light minerals, heavy minerals, mineral aggregates, lithic and shell fragments.

To sum up, considering that without a suitable recharge the sediments deposited during the first phase are still partially stable (around $50 \%$ was removed from the emerged beach and deposited in the opposite sea beds, on the foot of the submerged barrier and protected by it), IT was suggested using for the entire intervention the allochthonous materials, keeping the autochthonous ones for the recharge intervention that will have to be carried out by the local administration and trying to make it as cheap as possible.

From an environmental point of view, the area in which the intervention was put in place at the beginning lacked macroscopic flora and fauna and there were few zoomacrobenthos elements without real evidence of a biological chain, while from a functional point of view the area was not suitable for swimming, since the "uncomfortable" top of the outcrop of a quartzarenite level of the Capo D'Orlando Flysch emerged.

The part of the work already carried out underlined how the structure allows a natural sedimentation that takes a profile similar to the one of the neighbouring beaches (the ones in the south), where no protection structures were built. Moreover, the structure represents a good nursery area for young fish. The reef, built with natural rocks (basalt from Mount Etna) was perfectly colonized by the benthonic fauna.

\section{Conclusions: the lesson learnt and its regional applicability}

The intervention in Giardini Naxos is set within a EU finance programme that should have ended within the POR 2000-2006, but still has to be completed. This span of time and administrative alteration was due to the lack of a clear programme (Coastal Management Plan) organised before the financial opportunities, built and implemented with a continuous exchange of information between local administration and regional government.

The lack of a pre-existing plan led to the impossibility of checking on the aims reached both from a planning point of view and the success of the project on a local level.

The project and the resulting intervention on the coast of Giardini Naxos followed unique bureaucratic - technical procedures in the regional panorama, favoured by the attention of the local administration, but also the objective need to protect not only the shoreline, but also to 
rebuild the beach, which is the key for tourism in the area. Obviously the Bay of Giardini Naxos offers a wider tourism potential, but the beach represents its break point.

For this reason the intervention was supported by a study suitable to its technical needs, and it was imagined in order to satisfy the necessities of tourists and local inhabitants, in order to make the coast safe for swimmers.

The submerged barrier allowed to mitigate the local wave climate, in order to use the best sediments available in the submerged deposits. As a matter of fact, since the area lacked compatible material both from a granulometric and compositional point of view, a regional search was carried out leading to the use of materials located in the Termini Imerese Gulf.

This technical-administrative process pointed out the absence of a Coastal Management Plan and above all a Submerged Deposits Plan, which are fundamental documents in order to give operational instructions for local intervention, which sometimes does not have a valid reason to be started and is not supported by local and regional technical data for its right fulfilment.

Taking into consideration this experience, the "political part", after having acknowledged the technical problems, started a reform process concerning coastal management, within a wider system regarding the management of the maritime government properties, trying to link programming with economic exploitation of the beach.

\section{References}

A.A.S.T. (2010) - Bollettino Statistico. Servizio Turistico Regionale, Sicilia, Italia.

AMODIO MORELLI L; BONARDI G; COLONNA V; DIETRICH V; GIUNTA G; IPPOLITO F; LIGUORI V; LORENZONI S; PAGLIONICO A; PERRONE V; PICCARRETA G; RUSSOM; SCANDONE P; ZANETTIN LORENZONI E; ZUPPETTA A. (1976) - L'arco Calabro-Peloritano nell'orogene appenninico-maghrebide. Memorie della Societa Geologicaltaliana. Vol. 17 pag. 160. Italia

D'ARRIGO A. (1936) - Ricerche sul regime dei litorali nel Mediterraneo. Consiglio Nazionale delle Ricicerche, Cpmitati per la Geologia e per l'Ingegneria. Rome, Italia

JAMES J.R. (1975) - Techniques in Evaluating Suitability of Borrow Material for Beach Nourishment. In: Coastal Engineering Research Center, U.S. Army Engineer Waterways Experiment Station. Vicksburg, Mississippi.

LENTINI F., CATALANO S., CARBONE S. (2000) - Note illustrative alla Carta Geologica della Provincia di Messina. Scala 1:50.000. S.E.L.C.A. Firenze, Italia.

\section{Acknowledgments}

A special thanks goes to Prof. Laura Bonfiglio, Palaeontology full professor and expert of the regional geology, both for her general critical interpretation and for her useful geological notes that allowed to better set the intervention presented.

We would also like to thank P3A Engineering for having allowed us to use some of their images for our project.

Finally thanks to the Municipality of Giardini Naxos that allowed us to use all the material produced in the last ten years for the study of the coast of the Bay of Giardini Naxos. 